\title{
Correction to: Effect of mint oil against Botrytis cinerea on table grapes and its possible mechanism of action
}

Ren Xueyan • Song Dandan • Liang Zhuo •

Kong Qingjun

Published online: 9 November 2018

(C) Koninklijke Nederlandse Planteziektenkundige Vereniging 2018

Correction to: Eur J Plant Pathol

https://doi.org/10.1007/s10658-017-1375-6

The author name "Ren Xueuan" should be corrected and read as "Ren Xueyan".

The online version of the original article can be found at https://doi.org/10.1007/s10658-017-1375-6

R. Xueyan · S. Dandan · L. Zhuo · K. Qingjun $(\bowtie)$ College of Food Engineering and Nutritional Science, Shaanxi Normal University, Xi'an, Shanxi 710119, China e-mail: kqjboy401@126.com 